\title{
Henry Raper's Spherical Traverse Table
}

\author{
Charles H. Cotter
}

HenRy Raper (1799-1859) the eldest son of Admiral Henry Raper (17671845 ) retired from active service in 1825 , from which time he devoted himself to nautical science. He served repeatedly on the Councils of the Royal Geographical and Royal Astronomical Societies and for many years was Secretary of the Royal Astronomical Society. His Practice of Navigation and Nautical Astronomy earned him the award of the Gold Medal of the Royal Geographical Society.

The Spherical Traverse Table, which formed Table 3 in the first edition 1 of Raper's classic work published in $184^{\circ}$, was so named from its being used in conjunction with the plane traverse table for solving problems involving spherical trigonometry. A wide variety of problems for which the table facilitates solutions are given in the Practice.

Raper's work is a thoroughly practical manual of navigation; the explanations are models of conciseness and precision but the author gave little or no attention to the theoretical background of navigation nor to the proofs of the methods he described. Written during a period which, judging by the numerous investigations made at the time into astronomical methods of position finding at sea, may truly be called the golden age of nautical astronomy. Raper's work is a veritable treasure house of navigational brain-teasers for anyone having a taste for grappling with mathematical puzzles.

Among the problems which may be solved by inspection using the spherical traverse table are: given latitude, declination and altitude to find hour angle or azimuth; given latitude and Sun's declination to find the times of the beginning and end of twilight; and clearing a lunar distance observation from the effects of refraction and parallax. Curiosity almost compels one to ask the question: 'What have these (and many other) problems in common which allow solutions (relatively easy in most cases) by means of a comparatively simple double-entry table ?'. Raper never published a description of the principle underlying his spherical traverse table. His intention to do so in a work to be devoted to the theory of navigation was thwarted by his death in 1859 , but this principle may readily be described as follows, with reference to Fig. I.

Figure I illustrates any spherical triangle $A B C$ whose sides are denoted by $a^{\prime}, b^{\prime}$ and $c^{\prime}$, these being respectively the complements of angles $a, b$ and $c$. By the spherical cosine formula we have:

$$
\begin{aligned}
\cos A & =\left(\cos a^{\prime}-\cos b^{\prime} \cos c^{\prime}\right) / \sin b^{\prime} \sin c^{\prime} \\
& =(\sin a-\sin b \sin c) / \cos b \cos c \\
& =\sin a \sec b \sec c-\tan b \tan c
\end{aligned}
$$

and

$$
\begin{aligned}
100 \cos A & =(100 \sec b \sec c) \sin a-(100 \tan b \tan c) \\
& =M \sin a-N,
\end{aligned}
$$


where $M=100 \sec b \sec c$ and $N=100 \tan b \tan c$. Transposing formula (2) we have

$$
M \sin a=100 \cos A+N
$$

Formula (2) is adaptable for finding an angle in a spherical triangle given the three sides; formula (3) is adaptable for finding a side given the opposite angle and the other two sides.

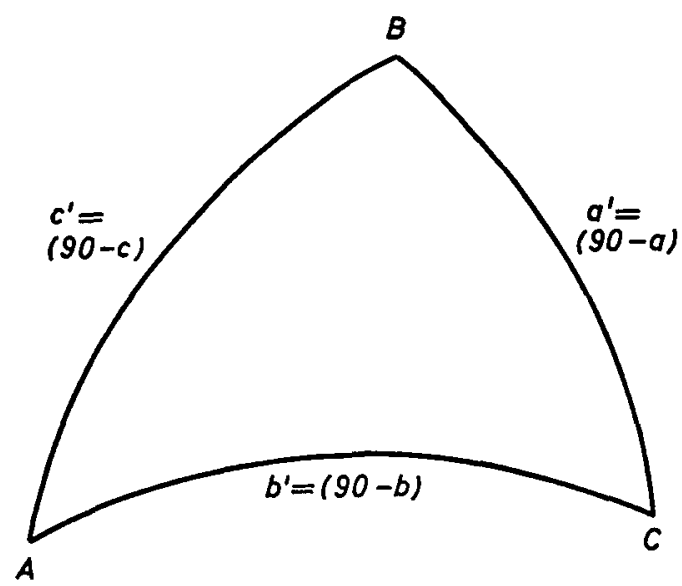

FIG. I

Raper's spherical traverse table is arranged to give, for arguments $b$ and $c$, respondents $M$ and $N$. A fragment of the table is illustrated below :

\begin{tabular}{c|c|c|c|c}
\hline$a \rightarrow$ & \multicolumn{2}{|c|}{$42^{\circ}$} & \multicolumn{2}{|c}{$43^{\circ}$} \\
\cline { 2 - 4 }$b \downarrow$ & $M$ & $N$ & $M$ & $N$ \\
\hline 0 & & & & \\
62 & 286.6 & 169.3 & $291 \cdot 2$ & 175.4 \\
63 & 296.4 & 176.7 & $301 \cdot 2$ & 183.0 \\
64 & 307.0 & 184.6 & $311 \cdot 9$ & $191 \cdot 2$ \\
\hline
\end{tabular}

The table is arranged to be entered with the smaller of the two arguments at the top of the page and the greater at the side. After having lifted the corresponding values of $M$ and $N$ recourse is made to the plane traverse table in which, if any given number as a distance represents the hypotenuse $h$ of a plane rightangled triangle, then $x$ and $y$ respectively correspond to $d$. lat and dep, and:

$$
x=h \cos \theta \quad y=h \sin \theta,
$$

where $\theta$ represents the angle opposite to side $y$; or what is in the plane sailing problem the course angle.

Considering formula (2): if the plane traverse table is entered with $a$ as 
course and $M$ as distance, $M \sin a$ is lifted from dep column. Now distance cos course $=\mathrm{d}$. lat, so that by entering the plane traverse table with 100 in the distance column and $(M \sin a-N)$ in the $d$. lat column, the corresponding course angle is $A$. Similarly for formula (3).

Raper considered that the utility and convenience of his spherical traverse table would recommend it to general practice. According to a footnote in the first edition of his Practice of Navigation Raper stated:

'If this table should be approved, it is the author's intention to publish, separately, the Plane and Spherical Traverse Tables, with their numerous applications, in an extended form ...'

This was never done by Raper, or by any of the editors who were responsible for the many editions of the Practice which were published after Raper's death. In the last edition, 2 which was edited by H. B. Goodwin and published in 1920, the spherical traverse table is identical with the original one of 1840 .

It is not unlikely that the idea for Raper's spherical traverse table stemmed from an interesting method ${ }^{3}$ for finding longitude by chronometer which appears to have been introduced in 1793 by Dr. Andrew Mackay (1760-1 809) of Aberdeen who made important contributions to the science of navigation and was 'a skilful, accurate and indefatigable calculator of mathematical tables'.

Mackay's method is an early example of a direct method of sight reduction in which three specially designed tables were provided. In the explanation of the use of his 'Tables for Computing Apparent Time', Mackay pointed out that:

'These tables may be also used for computing the true azimuth, the latitude from double altitudes of the Sun with the intermediate time, and for clearing the apparent distance from the effects of parallax and refraction.'

Mackay's tables are based on the formula:

$$
\cos P=\sin a \sec l \sec d \pm \tan l \tan d .
$$

This formula is equivalent to formula ( $I$ ) but it is derived from a $P Z X$-triangle in which $P$ denotes the hour angle of an observed body; $a$ and $d$ the body's altitude and declination respectively; and $l$ the observer's latitude. The first of Mackay's tables (Table 27) gives logarithmic values of sec lat. sec dec. against arguments latitude and declination, each at $\mathrm{I}^{\circ}$ intervals. The second table (Table 28) gives natural values of tan lat. tan dec. multiplied by 10,000, against arguments latitude and declination at $I^{\circ}$ intervals. The third table (Table 29) gives natural cosines, multiplied by 10,000 , against angles in hours, minutes and seconds, at 10 -second intervals. Mackay's rule for finding a body's hour angle (or meridian distance as this angle used to be called) is:

'Enter Table 27 with the declination of the object at the top and the latitude of the place of observation in the side column; take out the corresponding number, to which prefix the index 4 , and add it to the log. sine of the corrected altitude; find the natural number answering thereto, to which apply the number from Table 28 by subtraction or addition, according as the latitude and declination are the same or of contrary names. Now find the above difference or sum in Table 29 and the corresponding time will be the distance of the object from the meridian.'

The comparatively rapid method-involving only five table entries and two 
simple additions or subtractions-for solving hour angle, given latitude, declination and altitude, is illustrated by the following example:

Example: Find the hour angle of a star whose altitude and declination are respectively $53^{\circ} 19^{\prime} \mathrm{E}$. and $10^{\circ} 06^{\prime} \mathrm{S}$., the observer's latitude being $15^{\circ} 48^{\prime} \mathrm{N}$.

\begin{tabular}{llll}
$\begin{array}{l}\text { Tab. } 27 \\
\text { alt. } \log \sin \end{array} \frac{4.0235}{9.9042}$ & Tab. 28 & 0504 \\
sum & $\frac{3.9277}{2} \longrightarrow$ nat numb. & 8467 \\
H.A. $01^{\mathrm{h}} 44^{\mathrm{m}} 53^{\mathrm{s}} \longleftarrow$ Tab 29. & 8971 \\
\hline
\end{tabular}

The process of finding the azimuth of a star is almost identical with that for finding hour angle, the method in this case depending on the formula :

$\cos Z=\sin d \sec a \sec l \pm \tan a \tan l$.

H. B. Goodwin, in a paper ${ }^{4}$ published in 1900 , drew attention to several additional uses for which Raper's spherical traverse table could be employed. One of these is in connection with great circle sailing; Goodwin argued that it is important to know the rate at which the course angle on a great circle path is changing. It is readily demonstrated that:

$$
\text { change of course }=\text { change of lat. } \times \text { tan course tan lat., }
$$

a relationship which may readily be dealt with by means of column $N$ in the spherical traverse table. Thus the value of $N$ corresponding to a given course and latitude is the change of course angle corresponding to a change of 100 minutes of latitude.

An interesting use of the table in nautical astronomy is to find the rate at which a celestial body is changing its altitude. The table is entered with arguments latitude and complement of azimuth. The rate in minutes of arc per minute of time is then given by $1500 / M$. This follows because the rate of change of alt. $=15 \cos l \sin Z=15 / \sec l \sec \left(90^{\circ}-Z\right)$ in minutes of arc per minute.

Again, the table may be used to find the reduction to the meridian employing the dynamical principle first described by Goodwin, 5 which is based on the formula : $r=\frac{1}{2} d z . T$, in which $r$ is the required reduction; $d z$ is a function of the rate of change of altitude of the observed body; and $T$ is the body's hour angle in minutes of time.

Example: Required the reduction, given latitude $55^{\circ} \mathrm{N}$., declination $20^{\circ} \mathrm{S}$, , altitude $14^{\circ}$, hour angle $54^{\mathrm{m}}$.

(i) Find the body's azimuth. Using Burdwood's Table this is S. $13^{\circ} \mathrm{W}$.

(N.B. The determination of azimuth forms no part in the reduction problem since azimuth is required for laying down the position line.)

(ii) With arguments $(90-\mathrm{Az})$ i.e. $77^{\circ}$, and latitude $\left(55^{\circ}\right)$ lift $M(775)$.

Then

$$
\begin{aligned}
r & =\frac{1}{2} \times 1500 / 775 \times 54 \\
& =\underline{52 ! 3}
\end{aligned}
$$

Many of the problems which may readily be solved, at least approximately, through the agency of Raper's spherical traverse table are no longer the concern of practical navigators. Armed with a modern set of inspection tables, Nautical Almanac, sextant and timepiece, the present-day nautical astronomer is entirely 
self-contained. Methods such as Mackay's, and tables such as Raper's spherical traverse table, have long since passed into the rich history of science.

\title{
REFEREN CES
}

1 Raper, H. (1840). The Practice of Navigation and Nautical Astronomy. London.

2 Raper, H. (1920). The Practice of Narigation and Nautical Astronomy. 2 ist Edition by H. B. Goodwin.

3 Mackay, A. (1793). The Theory and Practice of finding the Longitude . . in two rolumes. London.

4 Goodwin, H. B. (1900). The uses of spherical traverse tables. The Nautical Magazine. Glasgow, Vol. 69 .

5 Goodwin, H. B. (1894). The 'Ex-Meridian', treated as a Problem in Dynamics. London.

\section{Progress in Port Approaches}

\author{
R. B. Richardson \\ (Port of London Authoritv)
}

DENSE fog prevailed over the whole of the Thames area for three days from I 518 on i 8 th through to 1900 on 2 ist December 1972, with no real clearances of significant extent or duration throughout this period. Such prolonged fog had not occurred there since December, 1962 .

It may therefore be encouraging to make some comparisons to help judge what progress has been made in port approaches in the decade involved and to draw what conclusions we can from this.

(1) In December, 1962, the service was still relatively new and only about 40 per cent of the shipping in the Thames was fitted with v.h.f. Approximately $5^{\circ}$ per cent was then fitted with radar.

(2) In December, 1972, with the service long established, over 90 per cent was fitted with v.h.f., and by this time approximately 90 per cent had radar.

(3) During three and a half days of continuous dense fog in December, 1962, records show only eight sea-going vessels moved in the river.

(4) During the three days in December, 1972, a total of two hundred and fifty-six sea-going vessels moved.

(5) As a recent comparison with (4), for the identical period in December 197I, which was clear weather throughout, the total movement was three hundred and seventeen vessels, so we see a very high proportion of the clear weather figures moving in fog, but under a controlled condition.

It is clear from this that there has been a dramatic long-run improvement in the facility and conduct of fog navigation in these waters since 1963-as was indeed the intention of the navigation services and of those owners who equipped their ships to modern standards.

The organizational and legal changes introduced from 1964 onwards, notably the enforcement of the 'clearway' channel and 'lay-by' anchorages and the wholly new powers of General and Special Directions for Navigation vested in the navigational authority since 1968 , have contributed greatly to this. It is through these powers that a measure of order and conformity, through man- 